\title{
Technologies for Supporting Creativity in Design: A View of Physical and Virtual Environments with Regard to Cognitive and Social Processes
}

\author{
Karima Toumi' ${ }^{1}$, Fabien Girandola ${ }^{2}$, and Nathalie Bonnardel ${ }^{3}$ \\ 1) Aix Marseille Univ, PSYCLE (Center for Research on the Psychology of Cognition, Language and Emotion), Aix-en-Provence, France; Aix \\ Marseille Univ, LPS, Aix-en-Provence, France; InCIAM (Institute of Creativity and Innovation of Aix-Marseille), Aix-en-Provence, France \\ 2) Aix Marseille Univ, LPS, Aix-en-Provence, France; InCIAM (Institute of Creativity and Innovation of Aix-Marseille), Aix-en-Provence, France \\ 3) Aix Marseille Univ, PSYCLE (Center for Research on the Psychology of Cognition, Language and Emotion), Aix-en-Provence, France; InCIAM \\ (Institute of Creativity and Innovation of Aix-Marseille), Aix-en-Provence, France
}

\section{ABSTRACT}

Creative activities are becoming more and more necessary in professional areas, such as in design, towards the development of new products that should be adapted to current (or future) users and usages. In a competitive context, it is crucial, especially for companies, to face the challenge of coming up with innovative products. However, creative activities are particularly difficult to perform, and they are associated with important risks. In this context, we report on major findings based on the analysis of designers' cognitive processes involved in creativity, which has led to the development of computational systems used in physical environments. We also present studies related to technologies that are used in virtual spaces in order to support creativity. This last kind of technology seems to be more and more promising in the actual societal context, which requires remote working, all the more so during the current health crisis. More specifically, we discuss how virtual environments, particularly those from multiplayer games, not only redesign the way individuals work but can also contribute to enhancing creativity. Finally, we suggest perspectives towards the development of innovative new tools that
\end{abstract}

aim to enhance creative performance in individual and collective situations.

\section{KEYWORDS:}

creativity, design, virtual environments, new technology, avatars

\section{Article history:}

Received: May 12, 2021

Received in revised from: June 17, 2021

Accepted: July 5, 2021

ISSN 2354-0036

DOI: $10.2478 /$ ctra-2021-0012

\section{Corresponding author at:}

Karima Toumi

E-MAIL: Karima.toumi@univ-amu.fr

Fabien Girandola

E-MAIL: fabien.girandola@univ-amu.fr

Nathalie Bonnardel

E-MAIL: nathalie.bonnardel@univ-amu.fr 


\section{INTRODUCTION}

Creative activities are becoming more and more necessary in professional areas, such as in design, towards the development of new products that should be adapted to current or future users and usages. In a competitive context, it is crucial, especially for companies, to face the challenge of coming up with innovative products. However, creative activities are particularly difficult to perform and they are associated with important risks. Indeed, these activities are based on complex cognitive processes and take place in a social context, in which both individual and collective creative activities occur depending on stages in the design process. This paper aims at exploring the usefulness of computer-aided design systems and immersive environments at the different stages of the design process. It also points out how these technologies can counter some of the problems that designers face in individual and collective situations, with regard to cognitive and social processes. Therefore, in the first part of this paper, we report on findings about individual creative design activities and difficulties encountered by designers, which underlaid the development of computational systems used in physical environments to enable creativity in design. In the second part, we report on difficulties encountered in collective creative design activities and describe studies related to technologies that can be used in virtual environments to overcome these obstacles. In the third part, we finally evoke perspectives related to the development of innovative new technologies that can also enhance creativity in design.

\section{FROM THE ANALYSIS OF INDIVIDUAL DESIGN ACTIVITIES TO THE DEVELOPMENT OF COMPUTATIONAL SYSTEMS TO SUPPORT CREATIVITY IN PHYSICAL ENVIRONMENTS}

Several studies have been performed on both professional designers and students in design to analyse cognitive processes involved in individual design situations (e.g., Bonnardel, 2000; Bonnardel, 2012a, 2012b; Bonnardel \& Bouchard, 2017; Bonnardel \& Gero, 2021; Bouchard, Camous, \& Aoussat, 2005; Gero, 2000; Gero \& Bonnardel, 2005; Suwa, Gero, \& Purcell, 1998; Visser, 1994). This understanding has also been used to develop technologies that aim to favour creativity in design (see, for instance, Bonnardel \& Zenasni, 2010). Main findings about individual design activities are first reported and, then, we give examples of systems that can help designers overcome certain difficulties they encounter.

\section{Processes involved in individual creative design and difficulties encountered by designers}

Gero (2000) proposed a framework called Function-Behaviour-Structure (FBS), which helps to locate where creativity can occur in designing. It is based on three ontological categories: Function $(F)$, which corresponds to the intention of the designer, Structure $(S)$, which covers the elements and 
their relationships that go to make up a design, and Behaviour $(B)$, which corresponds to the way the design works. According to this model, designers commence with requirements from the client or future users, which express their needs and desires. During a process called 'formulation', designers transform requirements into functions and expected behaviours of the future design product. Finally, during a process called 'synthesis', designers transform the expected behaviours into the structure underlying the design product.

To complement this view, we can refer to the A-CM - Analogy-making and Constraints Management - model (Bonnardel, 2000), which highlights the role of two cognitive processes that can allow the designers to extend their space of ideas and to orient their decisions: analogymaking (as well as associations of ideas) and the management of various kinds of constraints, either internal or external to the designers. These constraints are considered as playing an important and positive role in design activities since they can contribute to both divergent thinking (e.g., when constraints lead the designers to look for ideas in a conceptual domain that is far from the design current area) and convergent thinking (e.g., when constraints are taken into account by the designers for assessing their ideas or solutions and progressively restricting the research space of design solutions). Constraints that are taken into account and managed by the designers can thus be related to the function, the structure or the expected behaviour of the design (Suwa, Gero, \& Purcell, 2000).

In addition to these frameworks, some studies were conducted in order to analyze designers' own perceptions and mental representations of both their creativity and the stages in their creative design thinking process (Bonnardel et al., 2018). Towards this end, interviews and questionnaires were proposed to 25 professional designers (average of 14 years' experience in design). Results of this study highlighted three main stages in the creative design process, which all interact with each other: (1) definition and redefinition (or 'problem framing') of the creative design problem; (2) the generation of ideas in relationship with designers' openness to new experiences, and (3) selfevaluation by the designers of their own ideas or solutions, until they reach creative design solutions, i.e. that are both new and adapted to the design problem at hand. Such stages in the creative design process are in line with descriptions of creative activities (see Reiter-Palmon et al., in this issue), during which the problem solver starts by identifying and structuring the problem to reduce its ambiguity, (the problem construction stage) then generates many ideas (idea generation stage), which can happen in a variety of ways (e.g., during brainstorming sessions), to finally evaluate these ideas with regard to certain goals and decide whether to adopt it (idea evaluation and selection stage).

Specifically, we can elaborate on these stages in the case of creative design activities. Firstly, the definition and redefinition of the creative design problem (or 'problem framing') are central in creative design activities since the goals of a particular design task and the intended functions of the design to be produced are not fully defined at the beginning. Thus, design problems are considered as 'ill defined' or 'ill structured' (Eastman, 1969; Reitman, 1964). Therefore, a part of designing consists in constructing those goals and functions (which is called 'problem finding'; see Bonnardel \& Gero, 
2021). It is only through the design problem-solving process itself that designers can complete their mental representations by imagining, generating and choosing design options. Dorst and Cross (2001) described it as based on a coevolution of problem and solution spaces. It is also important to highlight the role of 'external representations' or intermediate objects (Bouchard, Camous, \& Aoussat, 2005) in the evolution of the designers' mental representations. External representations go from the first sketches performed by designers, at the beginning of the design process, to the development of the final product (or creative production) at the end of the process. These external representations constitute a form of external memory and their role is crucial since they allow the designers to modify their perception and mental representation of the design problem all along the design problem-solving process (Goldschmidt, 1991). Therefore, according to Schön (1983), designers develop a 'reflective conversation' with their sketches, which leads them to reach a new understanding of the design problem.

Moreover, concomitantly to the definition and redefinition of the design problem, designers have to generate ideas and to evaluate them in order to progressively choose one or more idea(s) they consider relevant to be developed. The main difficulties consist in reaching ideas that are both new and adapted to the design problem at hand (see, for instance, Bonnardel, 2012a). In particular, several studies (e.g., Chrysikou \& Weisberg, 2005; Jansson \& Smith, 1991) showed a robust effect called 'design fixation', which leads designers to reproduce design solutions they already know or to conform to examples provided to them, which goes against reaching creative ideas.

Therefore, in order to foster designers' creative processes, it appears necessary to help designers to open their research space of ideas. Towards this end, several experiments were focused on analogymaking and conditions that enhance or limit the designers' evocation process (e.g., Bonnardel \& Marmèche, 2004, 2005). Results obtained with professional designers showed that when they are provided with intra-domain sources of inspirations, a design fixation effect is observed, whereas if they are provided with inter-domain sources (presenting nevertheless an interest for the design problem at hand), these sources allow professionals to extend their research space of ideas and to reach more creative design solutions.

We also observed that designers encounter difficulties in evaluating their own ideas or design solutions (self-evaluation). It is especially the case when they have to conform to numerous and various constraints and criteria (Bonnardel, 1996). Indeed, frequently, designers have an incomplete and imprecise understanding of constraints and criteria that should be considered in specific contexts and it is even more difficult for designers that are novices in a design domain. Therefore it also appears useful to help designers to evaluate their own design solutions. Moreover, due to the interplay between these different cognitive processes, each designer constructs his/her own mental representations and, in fact, deals with a design problem that becomes specific to him or her.

Based on such results, we argue that it is necessary to provide each designer with technologies enabling creativity that are adapted to both the designers' characteristics and the stages of design in which they are engaged all along with the design problem-solving. 


\section{Examples of technology-based tools to support creativity in individual design situations}

To overcome some of the difficulties designers encounter in individual situations, different modalities of human-computer interaction and cooperation can be proposed (see, for instance, Bonnardel \& Bouchard, 2014, 2017; Bonnardel \& Zenasni, 2010; Burkhardt, \& Lubart, 2010).

Firstly, to promote the definition and redefinition of the design problem, we can mention a computational system called T'nD - Touch, and Design (Bonnardel \& Gero, 2021; Bonnardel \& Zenasni, 2010), which presents the interest of allowing human-computer interactions without using keywords, nor a mouse. Indeed, this system is based on designers' gestures and it allows them to virtually sculpt a block of material (with force feedback) in order to represent, in virtual 3D, the object to be designed on the computer screen (see Figure 1). This appears to be a way to foster the externalization of ideas since designers can interact with the computational system without mobilizing a lot of attentional resources for the interaction to the detriment of the design problem-solving. Therefore, the designer's attention can be fully focused on the design problem solving and his/her perception and understanding of the design product in progress. It also allows a 'reflexive conversation' between the designer and the model he/she is developing. While using $\mathrm{T}^{\prime} \mathrm{nD}$, the designer gets both visual feed-back (on the screen) and haptic feed-back (through force-feedback devices) related to the model in progress, which allows him/her to infer new elements of understanding about the object to be designed.

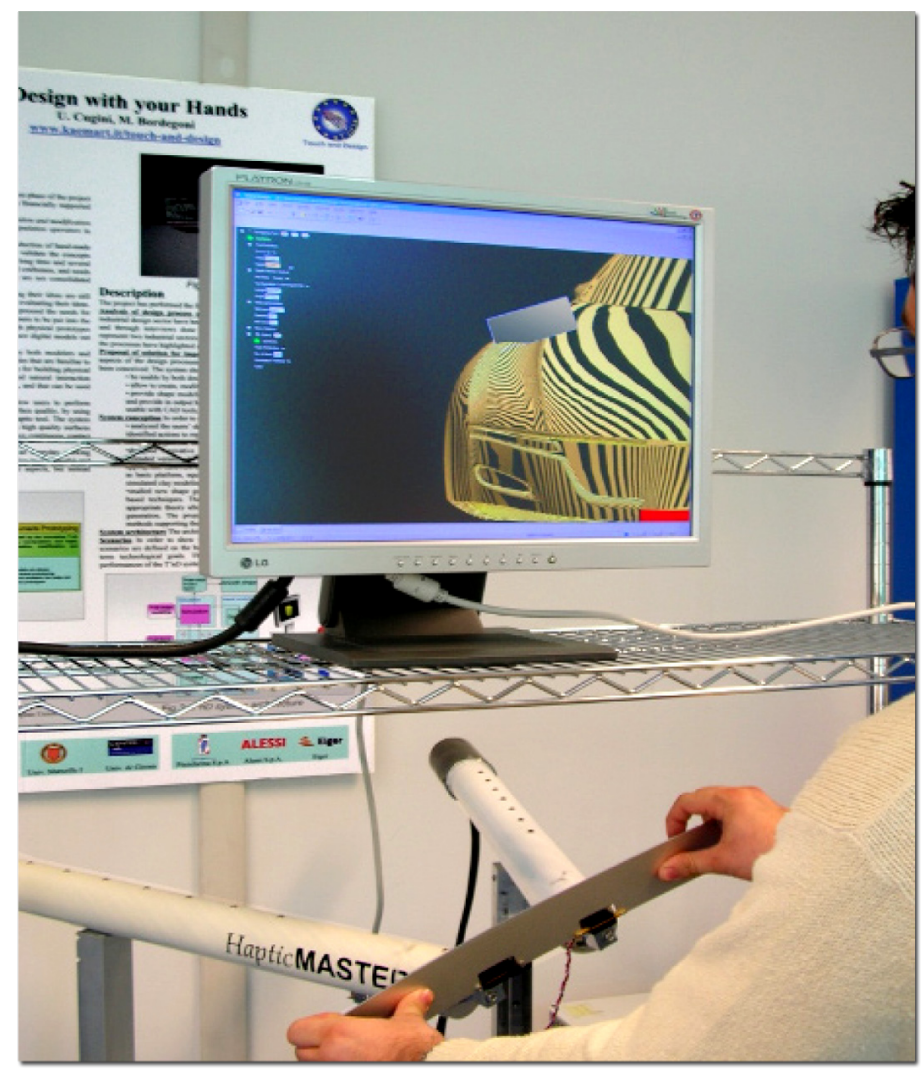

Figure 1. The Touch'n Design system

Source: Bonnardel and Zenasni (2010) 
Secondly, to favour the evocation of new ideas and encourage designers to enlarge their research space of ideas, two kinds of computational systems can be mentioned: one is based on the suggestions of images and the other one of the suggestions of words and relationships among them. More precisely, the TRENDS system provides designers with possible sources of inspiration in the form of images, which are extracted from the web in real-time (Bonnardel \& Bouchard, 2011, 2014, 2017; Bouchard \& Omhover, 2016). This technology can enable designers to engage in analogy reasoning and, in particular, to exploit inter-domain analogies to evoke ideas or solutions that are far from the conceptual domain of the design problem at hand (see Figure 2a). Another computational system, called SKIPPI, also provides designers with possible sources of inspiration but they consist of different kinds of words (Bonnardel \& Bouchard, 2014; Bouchard et al, 2017). More precisely, this technology enables designers to navigate in a graph of words implementing heterogeneous knowledge (see Figure 2b), for instance, regarding the product's characteristics, such as shape or colours, which can convey emotions to end-users, as well as the product fabrication process or values associated to the product's mark.
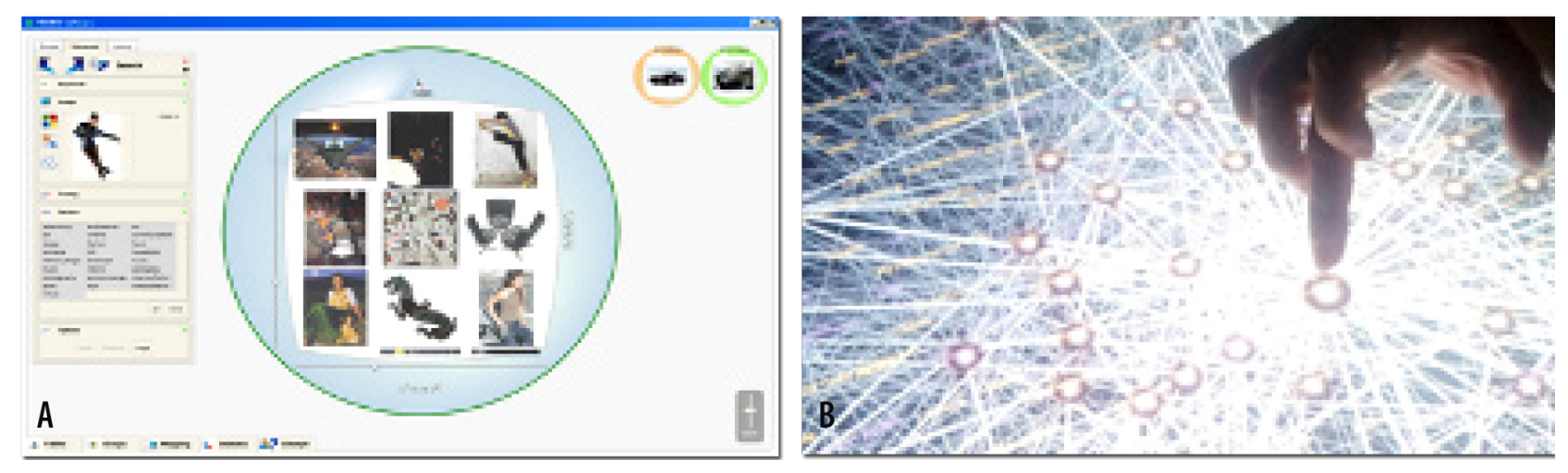

Figure 2. A) The TRENDS system, B) The SKIPPI system

Sources: Bonnardel and Bouchard (2014) www.trendsproject.org and www.skippiproject.com

Thirdly, to favour the evaluation of design solutions, we can evoke critiquing expert systems', which have been developed to help designers to more completely assess their design solutions (Bonnardel \& Zenasni, 2010). Towards this end, the computational system analyses in real-time the design solutions that are constructed by designers and, with regard to the knowledge-basis implemented in the system, it provides the designer with 'critics' or 'critiquing messages', which highlight solutions' drawbacks (e.g., when characteristics of the design solution do not respect constraints that are considered as relevant in the domain). 


\section{FROM THE ANALYSIS OF COLLECTIVE CREATIVE DESIGN ACTIVITIES TO TECHNOLOGIES TO SUPPORT CREATIVITY IN VIRTUAL ENVIRONMENTS}

In this section, we point out difficulties encountered in collective creative design activities and give examples of technology-based support to overcome these obstacles. In addition, we highlight the positive effects of virtual environments not only on creative design activities but also on remote work.

\section{Difficulties encountered in collective creative design activities}

'Two heads are better than one' or 'there is safety in numbers' are maxims that remind us that we often need others to solve problems, especially for an inherently complex activity like design. In fact, numerous research has shown that group members can facilitate the emergence of creative design ideas and lead to new productions (e.g. Fischer et al., 2005). However, despite the beneficial impact of the group on collective intelligence, the presence of a group in itself can bring new challenges that can impede the idea generation stage in a collective setting. As a matter of fact, Paulus and Kenworthy (2019) show, for example, that participants generate fewer ideas when they work in groups than when they work separately and subsequently combine their ideas (i.e., nominal groups, Paulus, Larey, \& Ortega, 1995; Ziegler, Diehl, \& Zijlstra, 2000). In addition, in accordance with general findings obtained in collective creative situations, we discuss how communication between different members of a design team can negatively impact individual idea generation and, thus, the creative design process.

One of the collective design challenges is to face production blocking. This occurs when an individual in group discussion blocks or prevents others from coming up with ideas. Group discussion can also lead to social inhibition. This happens when the fear of negative appraisal from other members of the group results in decreased performance. Nemeth and Nemeth-Brown (2003) observed that the anticipation of the group's judgment can lead to poor creative performances, especially when these ideas are 'unusual'. Solutions that are not common are less likely to emerge in collaborative situations where participants or stakeholders tend to give socially desired responses. This is particularly true when stakeholders come from different fields or have different levels of expertise. This leads to additional comprehension and communication problems (Nijstad, Stroebe \& Lodewijkx, 2003). Among the processes that can inhibit idea generation, there are also social loafing (i.e., the tendency of individuals to put in less effort when working in a group than when working individually), cognitive interference (i.e., when ideas generated by other participants or delays in expressing one's own ideas interfere with an individual's idea generation) and the communication speed (the need and time to type words may inhibit idea generation by slowing down communication).

In addition to these difficulties, we can point out the fact that design teams are more and more frequently geographically distributed (see Maciver \& Malins, 2016). Thus, they have to rely 
on computer-supported cooperative platforms (e.g., video conferencing systems) and on tools for distributed creative collaboration (e.g., electronic brainstorming). This is particularly true in the actual context, where the Covid-19 pandemic has brought a drastic change in the way people work, forcing them to move to an online format. Despite the different advantages of remote work, this digital shift imposes further challenges to co-design processes (i.e. as processes of creative cooperation), especially because the virtual communication can lead to a loss of information. Indeed, unlike in face-to-face situations, designers engaged in virtual exchanges may lack certain references, such as nonverbal communication, and frequently cannot use a common information medium (Chinowsky \& Rojas, 2003; Forens et al., 2015; Kirkman \& Mathieu, 2005). This leads to a particularly challenging situation for designers since communication is a fundamental element of group creativity.

\section{Examples of technology-based tools to support creativity in collective design situations}

To help professionals generally and designers particularly inject creativity into their projects and facilitate remote collaboration (Bonnardel \& Pichot, 2020), we consider that the digital shift requires immediate attention and investment. In this sense, we introduce different technology-based tools that aim to assist teamwork and support creativity during the design process.

\section{Electronic brainstorming}

Researchers have long focused on how to improve communication in order to improve group creativity (Paulus \& Nijstad, 2003). For this aim, they suggest using different techniques, among them the princeps brainstorming method (Osborn, 1963), which is intended to improve idea generation in groups. However, while this technique contributes to improving performance (gain process), it can also lead to factors that detract from performance (loss process) (Paulus \& Brown, 2007) and this appears specifically important due to the different challenges we mentioned before.

To avoid or reduce possible difficulties in collective design activities, some authors suggest to partially or totally use computer-mediated environments. Dennis and Wixom (2002) showed, for example, that electronic brainstorming (EBS), i.e. virtual sessions where group members generate ideas simultaneously, allows users to generate more ideas than in the classical/verbal brainstorming version (team members verbally express ideas one at a time), and as many or more ideas than during a nominal brainstorming (when members generate ideas individually). EBS is considered to be a more effective approach because it gives the advantages of working alone as well as the benefits of being with the group. Thus, it should be used when the goal is not only to increase creativity but also to support designers during the idea generation phase. Moreover, the anonymity that can be offered by such an interface can help to overcome some problems related to collective design situations, like evaluation apprehension (Sosik et al., 1998). It can also improve performance in later stages of the design processes, such as decision-making and planning (Maaravi et al., 2020).

This enhancement in creative idea production relying on EBS may be explained by different reasons. To begin, displaying a large number of ideas on a computer screen (see Figure 3 ) is easier to manage and it allows participants to pay more attention to one another's ideas (Michinov, 
2012) in contrast to a physical condition with scattered sticky notes all over the wall. A recent study (Jensen et al., 2018) compared physical and digital sticky notes in collaborative ideation and found, for example, that the virtual format allowed more note interactions (easier handling of the digital notes) and potentially supported more the grouping and the labelling phases of ideation. In the same line, the digital format allows more individuals to participate in the brainstorming session, which makes them exposed to a larger number of ideas, thus facilitating the idea generation process (e.g., Paulus, Kohn, Arditti, \& Korde, 2013). Moreover, since all participants can generate ideas simultaneously without waiting for their turn to speak, it seems possible to avoid phenomenons like the production blocking previously introduced (e.g., Michinov \& Primois, 2005). Finally, among the processes stimulating the idea generation or the performance (process gains) during an electronic brainstorming (Dennis, Minas, \& Williams, 2019), we can mention cognitive stimulations (i.e., the ability of one participant's idea to trigger a new idea in another participant) and social comparison and facilitation (when the presence of others improves performance).

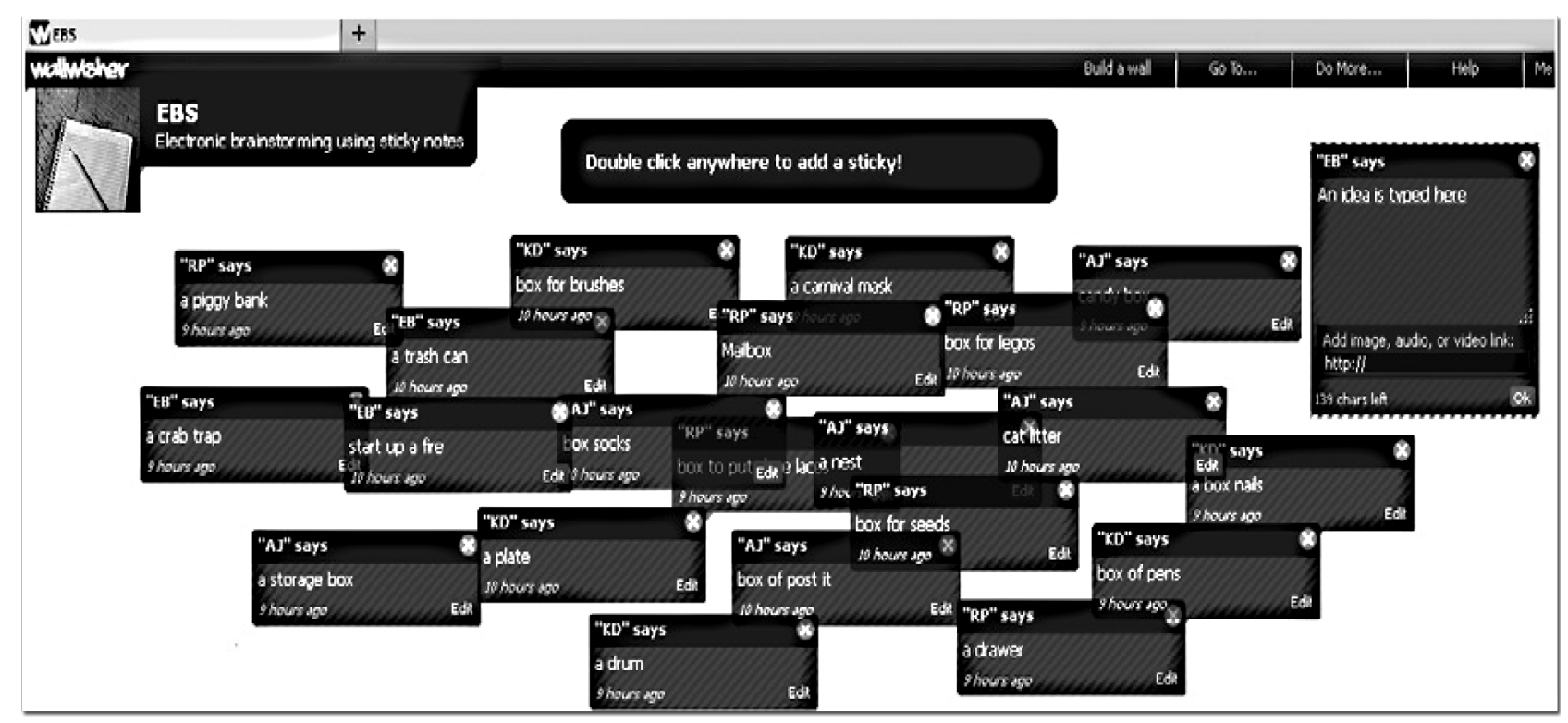

Figure 3. Screen Capture of an electronic brainstorming

Source: Michinov (2012)

However, and just like the classical brainstorming, EBS does not solve the social loafing problem (Buisine, Guegan, \& Vernier, 2017). In this context, different studies suggest that group cohesiveness and sense of belonging to the group can reduce or eliminate social loafing (Karau \& Hart, 1998; Karau, \& Williams, 1997; McKinlay et al., 1999). This explains why when participants are interacting with one another only in a computer-mediated condition, they may feel less concerned than in a face to face situation and there may be lower levels of perceived belonging to the group and group cohesiveness leading to social loafing (McKinlay et al., 1999).

In such contexts, Buisine, Guegan and Vernier (2017) suggest using a new kind of brainstorming that relies on avatars to support both remote collaboration and group identification. We describe it below. 


\section{Avatar-mediated brainstorming}

Avatar mediated brainstorming (e.g., Buisine, Guegan, \& Vernier, 2017; Marinussen \& de Rooij, 2019 ) is an emerging creativity support tool that consists in using avatars to generate ideas within the group, inside a virtual world or virtual reality space. To briefly define these terms, virtual worlds (VW) are computer-based three or two-dimensional environments that can replicate the real world and where users represented by avatars interact and communicate simultaneously or synchronically (Akchelov \& Galanina, 2016). Virtual worlds are also a subset of multi-user virtual environments (MUVE) (for more details, see Girvan, 2018) and they generally refer to persistent online social spaces, like Second life (Schroeder, 2008). In addition, virtual reality (VR) is a technology that can be used to immerse the user in the virtual world. For this aim, different VR technical systems can be used (e.g., Oculus rift or HTC Vive) to make the user physically feel present (as an avatar) in a non-physical world.

We focus here on the positive effect of avatar-mediated brainstorming held in the virtual world (computer desktop) on creative idea generation and group cohesion. Recently, BourgeoisBougrine et al. (2020) analyzed the use of multi-user virtual environments (MUVE) and their impact on creativity. More precisely, they compared brainstorming sessions occurring in a real meeting room (RE) and in a similar meeting room presented in a virtual environment (VE). The results show that fluency and originality are significantly higher in the virtual situational than in the real one. The participants placed in a virtual environment and who had a high risk-taking propensity were the most creative (with regard to fluency and originality). Thus, the virtual environment disinhibited participants with a high propensity to take risks, leading to divergent thinking and mental flexibility. In the same line, Wiederhold (2013) compared participants' performance in a brainstorming task and in a negotiation task while using either a video conference software (i.e. skype) or gesture-based avatars. The results indicate that the skype condition led to a greater number of ideas but the avatar condition led to higher quality ideas and to a more positive change of the partner's perception. Other experiments performed by Guegan et al. (2017) and Buisine and Guegan (2020) investigated the effect of social identity cues (SIC) manipulation on creative performance and group identification in both physical and virtual groups. The results of their study suggest that having SIC (i.e., clothing that holds a strong and positive social identity for the target population) increases the creative ideas generation in both real and virtual conditions; however, it enhances group identification only in the digital format. Finally, the visual features of the virtual environment can also come into play and lead to higher creative performance through a priming effect (e.g., Bhagwarwar, Massey, \& Dennis, 2013).

\section{Dynamic personas}

Other studies based on avatars tend to show the interest of their use for supporting creativity in collective design situations. It is especially the case of the use of avatars consisting in 'dynamic' personas (Bonnardel et al., 2016; Bonnardel \& Pichot, 2020). Dynamic personas are inspired by the 'method of personas', which is based on classical or 'static' persona, and more and more used in user-centred design contexts. When applying this method of personas, designers and other 
stakeholders (e.g. ergonomists, engineers) are provided with fictional characters or archetypes of future users, to favour their understanding of the users' expectations and needs (Miaskiewicz \& Kozar, 2011). Usually, classical personas are given a proper name and they are represented with a photo accompanied by information elements related, for example, to their specific behaviours, expectations and fears (Pruitt \& Grudin, 2003). This method aims to enhance the designer's empathy as well as creativity during the design process (Brangier, Bornet, Bastien, Michel \& Vivian, 2011). However, the designer is generally not involved during the data/information collection and can be considered as relatively 'passive' (Goh, Kulathuramaiyer \& Zaman, 2017). Thus, Bonnardel et al. (2016) proposed a new method, based on 'dynamic personas', designed to address this issue by moving from static mode (classical method), where the designer reads textual information about the end-users (see Figure 4a), to a dynamic dimension where he/she actively exchanges with an avatar providing him/her with a virtual and dynamic representation of a future user (see Figure 4b). In this last case, the dynamic persona leads designers - and other stakeholders - to become more active in their search for information and to better integrate and use this information in their proposals for solutions (Bonnardel et al., 2020). An exploratory study conducted with a small number of professionals (Bonnardel et al., 2016) and an experimental study with large groups of students (Bonnardel \& Pichot, 2020) tend to show that the use of dynamic personas would foster creativity, as analysed with regard to fluency (i.e. number of the generated ideas), statistical originality, and/or quality of creativity. Moreover, the use of a dynamic persona seems also to enhance the empathy towards personas representing future users and to lead to a higher quality of collaboration, in comparison with the use of a static persona.

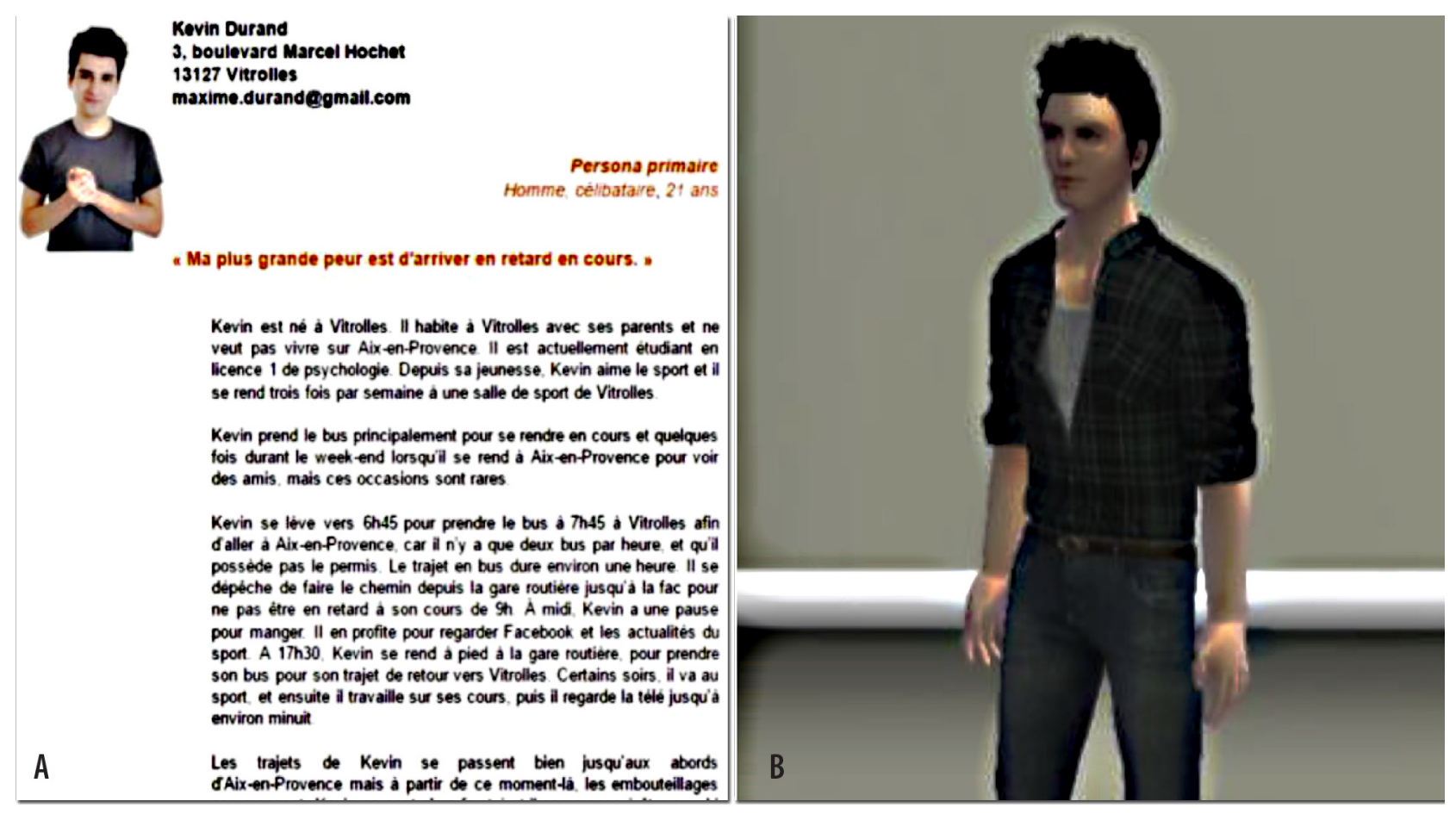

Figure 4. A) The static persona condition, B) Avatar of the dynamic persona

Source: Bonnardel and Pichot (2020) 
Thus, the dynamic persona method seems to be a powerful tool to foster certain dimensions of creativity and group dynamics in collective design situations. This gives rise to a complementary issue (will be addressed in section 3): As we embody avatars to represent ourselves in a computermediated environment does our attitude and behaviour change in relation to our virtual persona?

\section{The benefits of virtual worlds for remote work and design}

Since it's becoming clear that virtual communication will be a long-term reality (Barrero, Bloom \& Davis, 2021), having the right technology is critical to fully take advantage of remote work without it being detrimental to the individual's mental or emotional health. In this context, virtual environments offer ways to deal with the challenges virtual teams are facing, like communication, interaction, and technological limitation (Davis, Murphy, Owens, Khazanchi, \& Zigurs, 2009). Indeed, collaborative design environments (Merrick et al., 2011) can be based on virtual worlds (VW).

Unlike computer-aided design (CAD) applications, virtual worlds are considered as very accessible platforms, which do not require high hardware, nor an expertise in technologies (Koutsabasis et al., 2012). Moreover, different authors suggest that VW can support the design process. To begin with, 3D visualization platforms can allow the designers to communicate their ideas not only with other experts but also with the end users (Koutsabasis et al., 2012). For this reason different companies are using VW, like Second Life, for the evaluation of their future products (Kohler et al., 2009). Relying on VW can also be particularly interesting for design teams because they can manipulate virtual artifacts of their own products (Boughzala, de Vreede, \& Limayem, 2012). While embodying avatars (in first or third person view) designers are not just viewers of their product: they become also a part of the virtual space and they can manipulate objects (Koutsabasis et al., 2012), which allows them to get a better understanding of the artifact (e.g., a better appreciation of the object size next to an user represented by an avatar). Moreover, some studies have shown that the cognitive load of processing events in 3D virtual worlds is lower than processing events in 2D displays (Dan \& Reiner, 2017). In this sense, virtual worlds can probably be used to counter the high cognitive load generated during video conferencing (e.g., Muller et al., 2021) and, thus, possibly to avoid phenomenons like 'zoom fatigue' (Fauville et al., 2021; Toney, Light, \& Urbaczewski, 2021). A high cognitive load can impair team performance (Funke \& Galster, 2009) and decreasing it could reduce certain difficulties encountered by designers, like design fixation (Moreno, et al., 2015). Virtual worlds are also a powerful communication tool as they offer real communication in virtual spaces, with a high-fidelity embodied avatar with lip-syncing and expression capabilities. Similarly to a face-to-face situation, they allow users to interact using nonverbal social and interactional cues (Aneja, McDuff, \& Shah, 2019). The anonymity provided in virtual environments can also help to reduce other difficulties inherent to collective design activities, like the evaluation apprehension (Nunamaker, Dennis, Valacich, Vogel, \& George, 1991), thus leading to greater social disinhibition (Suler, 2004). Koutsabasis et al. (2012) analyzed designers' work inside virtual worlds and found that these spaces enhanced the design team communication and were perceived as satisfactory collaboration environments by the designers. In addition when collaborating remotely, designers 
seem to be more interested in seeing the avatar in the virtual world rather than seeing each other's face on the video screen (Gül \& Maher, 2009). In the same line, Raveendhran, Fast and Carnevale (2020) showed that when the contexts require frequent monitoring, leaders prefer interacting with their subordinates virtually via avatars rather than having face-to-face interactions, and this effect seems due to increased concerns about negative social evaluation. Next to communication, virtual worlds can also support collaboration, as design teams can co-construct artefacts at the same time but also immediately track each other's actions. Moreover they can provide emotional support (Khosravi et al., 2016) and reduce the level of loneliness (O'Connor et al., 2014), which is a particularly important advantage for professionals, especially, in the actual context where the outbreak has left many people isolated and lonely (Banerjee \& Rai, 2020; Carillo et al., 2020; Banerjee \& Rai, 2020). Finally, we consider that, even though these characteristics are not specific to virtual worlds, the particularity of VW is to integrate all of them (Koutsabasis et al., 2012) which can potentially support the design process.

\section{PERSPECTIVES TOWARDS THE DEVELOPMENT OF IMMERSIVE NEW TECHNOLOGY-BASED TOOLS TO SUPPORT DESIGN AND CREATIVITY}

To complement this overview of technologies to support creativity, we now focus on two recent innovative systems: virtual reality (VR) and holographic technology.

\section{Virtual reality to support the design process and to foster creativity}

Because of the high costs of virtual reality systems in the 1990s and 2000s, and the technological limitation of hardware (e.g., heavy, low resolution), much of the previous research in that field was limited in terms of application (Coburn et al., 2017). Nowadays, the high quality and relatively lowcost of hardware makes different authors argue that virtual reality (VR) technology can be used daily by designers. In the same line, we suggest that VR is potentially beneficial for designers in various stages of their work.

Having a deep understanding of designers' cognitive processes is mandatory to develop new systems that aim to support design activities. However, the capture of such processes can be very difficult as the 'traditional' manual methods can be pricey, time-consuming and especially intrusive (e.g., interruption of the designer during the design task). Sung et al. (2009) suggest relying on virtual reality (i.e., a cable harness virtual reality design and manufacturing system) because it allows a new kind of non intrusive capture and analysis of the design process. In addition, virtual reality has the advantage of reducing the design development time and its cost while increasing the product quality (Tao et al., 2018). Moreover, this technology can be implemented in the various stages of the design process and, according to certain authors, virtual reality 'will become widely used throughout industry as a major part of the product life cycle process' (Sung et al., 2009). 
To begin with and according to the creative design stages described in section 1, the VR can promote (1) the definition and redefinition of the design problem. Visualizing 3D objects inside an immersive virtual environment, rather than a 2D interface (3D modeling applications), is less demanding in terms of spatial reasoning skills and it allows users to work more naturally (Coburn et al., 2017). Thus, VR has the potential to foster the externalization of ideas since designers would allocate more attentional resources to design problem-solving.

Moreover, VR enriches designers' mental representations. As previously mentioned, designers aim to create user-centered products that answer to the needs of the target population. For this aim, they can use different tools, like static or dynamic personas to enhance empathy towards their product end-users. But what would favour empathy more than directly 'stepping in the shoes of these users'? VR has the ability to create an illusion of ownership over the virtual body (Bertrand et al., 2018). The latter can be infinitely customized to represent different users, whether children, elders or people with disabilities, and thus help designers reply to their specific needs.

Next to promoting the definition and redefinition of the design problem, avatars can be used to favour (2) the evocation of new ideas and make designers more prone to enlarge their research space of ideas. We first report on how embodying avatars can influence the attitudes and behaviours of users. Then we show how using creative virtual avatars can make the designers more creative.

Some studies showed that people's clothing can have a significant impact on their behaviours in real-life contexts (see Frank and Gilovich, 1988; Johnson \& Downing, 1979). In line with this observation, Yee and Bailenson (2007) were the first ones to test this phenomenon in a virtual environment. Their main question was 'As we change our self-representations, do our selfrepresentations change our behavior in turn'. To respond to this question, the authors carried out two studies. The first experiment showed that when people embody an attractive avatar they appear friendlier and give more personal information about themselves during disclosure and an interpersonal distance task than those who embodied an unattractive one. Similarly, the participants who embody tall avatars (second experiment) are more confident and tend to be more aggressive during a negotiation task than those who embodied shorter ones. Surprisingly, this effect continues to exist outside the virtual environment. These experiences show that people "conform in behavior and attitudes to their avatars' characteristics" (Ratan, Beyea, Li, \& Graciano, 2020). The authors called this phenomenon "The Proteus Effect" as a reference to the Greek God of metamorphosis.

Complementary studies performed by Banakou, Kishore, and Slater (2018), showed that 'virtually being' Einstein (see Figure 5) and, thus, embodying an avatar that is stereotyped as intelligent, improves the participants' cognitive performances in a cognitive task.

Along the same line of the previous research, some authors designed avatars to influence users' creativity and answer the following question: Would embodying avatars that are seen as creative enhance creativity? Guegan et al. (2016), through a first study, tried to identify what a creative avatar may look like for the engineering students' population. An online survey allowed them to select avatars representing inventors (e.g., white blouse). Then, they showed that when students embody 
these avatars in a brainstorming creative task, they generate more creative ideas (in terms of fluidity and originality) than when they use neutral avatars or in a face-to-face condition.

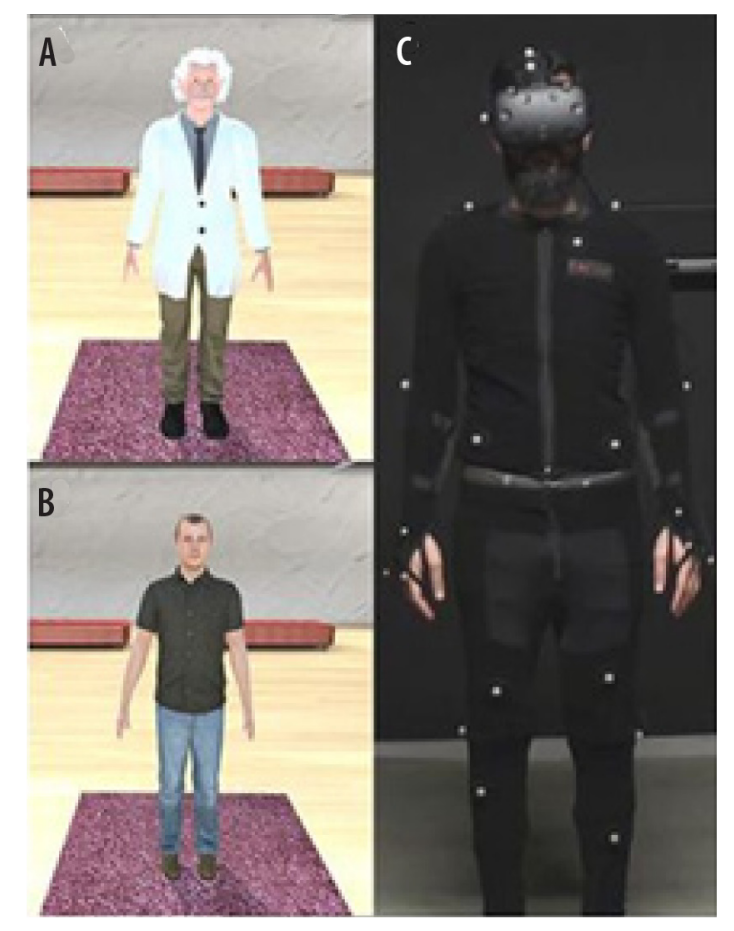

Figure 5. Participant fitted with an HTC VIVE head-mounted display, and a body motion tracker, in both neutral and Einstein condition

Source: Banakou, Kishore, and Slater (2018)

Virtual reality can also be a powerful inspiration tool. As mentioned previously, some CAD (computeraided design) systems like TRENDS or SKIPPI can support the idea generation during the design process by offering different sources of inspiration. Introducing VR to this stage offers to designers a full immersive experience, in which they can simulate situations that are impossible to experience otherwise (e.g., zero gravity) and where they can directly interact with artifacts that can be placed in environments which would not naturally be found together (Coburn et al., 2017). This could have the potential to enhance inspiration more than non-immersive methods of design inspiration.

Finally, virtual reality can favour (3) the evaluation of design solutions. Designers resort more and more to VR because it allows them to view and evaluate their products without building or modifying any physical model (Abdelhameed, 2013). It also offers the possibility to view products at any desired scale. For example, a study performed at Volvo showed that when designers view a car body at a full scale, it helps them to better evaluate its aesthetics, in comparison with the traditional situations. The virtual visualization can also help to identify hidden design issues (Liu et al., 2014) and test the usability and ergonomics of a design by simulating product-user interactions (Coburn et al., 2017). VR is not only a powerful communication tool between experts but also with endusers. Bakr et al. (2018) showed, for example, how VR allows kids to participate in the conception phase of a kindergarten by evaluating the designers' work. 
Moreover, thanks to the real-time monitoring of designers' actions and functions (automated task analysis and process mapping) offered by virtual reality, a 'help design information "push" system' could be created (Sung et al. 2009). This virtual aided-design (VAD) system can transfer the knowledge captured from experts during design sessions to novice users, to help them perform similar design tasks. In the same line, VR can be used to favour processes useful to 'embrace creativity'. The Covid-19 pandemic has forced cultural institutions to explore alternative digital spaces. Thus, we see many museums using virtual mediums to inspire creativity by offering online tours and exhibits. Virtual reality is also fast becoming a formidable medium of artistic expression, making the user go from a 'viewer-of-art' to a 'maker-of-art' (Pissini, 2020). Indeed, more and more artists are already breaking new ground and creating amazing work with it. In this context, Google has launched Tilt Brush, a virtual reality painting tool that allows the user to unleash his/her creativity and paint in 3D space. In the same line, many scientists are trying to use VR to support and train artistic skills, for example, through works like 'The painter project' (Gerry, 2017). In this virtual environment, users (novice group) embodied the first-person point-of-view of painters (expert group) and simultaneously saw a tracked rendering of their own hand while they painted on a physical canvas (see Figure 6). The results of this exploratory study suggest that VR and, particularly, embodied experiences (Ahn, Le, \& Bailenson, 2013) can be a powerful tool to, in some way, contribute to 'teach' creativity and enhance empathy. In addition, it can also be used as a new expert-novice mentorship simulation, going from a situation where students watch and replicate the instructor's work, to the illusion of being him/her and embodying his/her perspective.

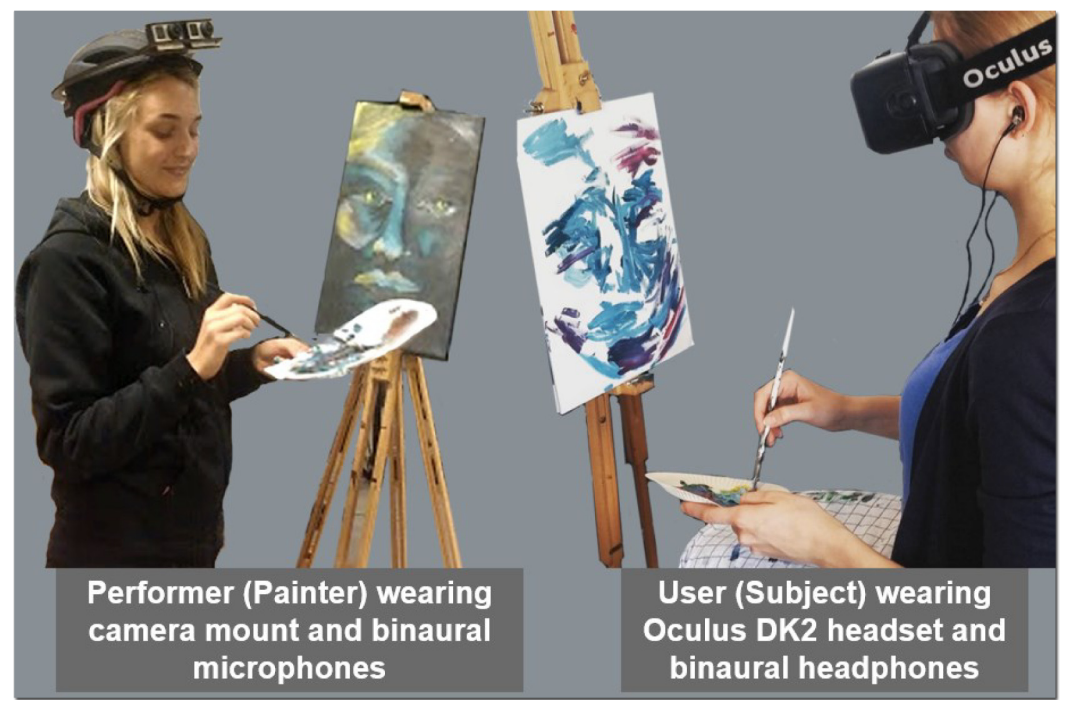

Figure 6. A view of the experimental setup of the painter project

Source: Gerry (2017)

In the same line, Guan et al. (2021) studied the effect of VR on creativity during a pottery class. For this aim, the authors compared a classical paper-and-pencil approach to a VR-based one and found that the latter led to more creative productions but also to higher behavioural, cognitive, emotional, and social engagement. 


\section{Holographic technology}

Today some technologies like virtual reality or holographic technology, give the promise to create visual experiences that compete with real-world ones and thus signal the beginning of a new communication era reshaped by the technology (Lee, 2013). Holography is a method used to record patterns of light. These patterns are reproduced as a three-dimensional image, called a hologram (Elmorshidy, 2010). When using a holoprojector, large-scale high-resolution images are projected onto diverse surfaces. For example, almost 15 years ago, Bill Gates used this technology to appear virtually at the World Congress on Information Technology, in Kuala Lumpur. In line with it, a French candidate for the 23rd French presidential election appeared on stage as a hologram and held simultaneous campaigns in seven places at once. Many other examples of celebrities emerging 'from nowhere' could be cited but maybe what is the most surprising about this technology is that it can also give the impression to resuscitate dead people, like Tupac Shakur who appeared as a hologram at the 2012 Coachella music festival. It can also give life to non-humans and make them idols followed by millions of people. One of the most noteworthy examples of how cybernetics has changed the way we perceive virtual characters is probably Hatsune Miku, a Japanese Vocaloid (a voice synthesizer program) developed by the Japanese Future Media company Crypton and by Yamaha. Hatsune Miku is not a person. Still, she owns the largest song catalogue in the history of the world, with over 100,000 songs and 170,000 YouTube videos (Halo \& Matsutoya, 2019), which have garnered over 100 million Youtube views (Hayashi, 2021). In Figure 7, we can see an image from a live performance given by Hatsune Miku in London in 2018.

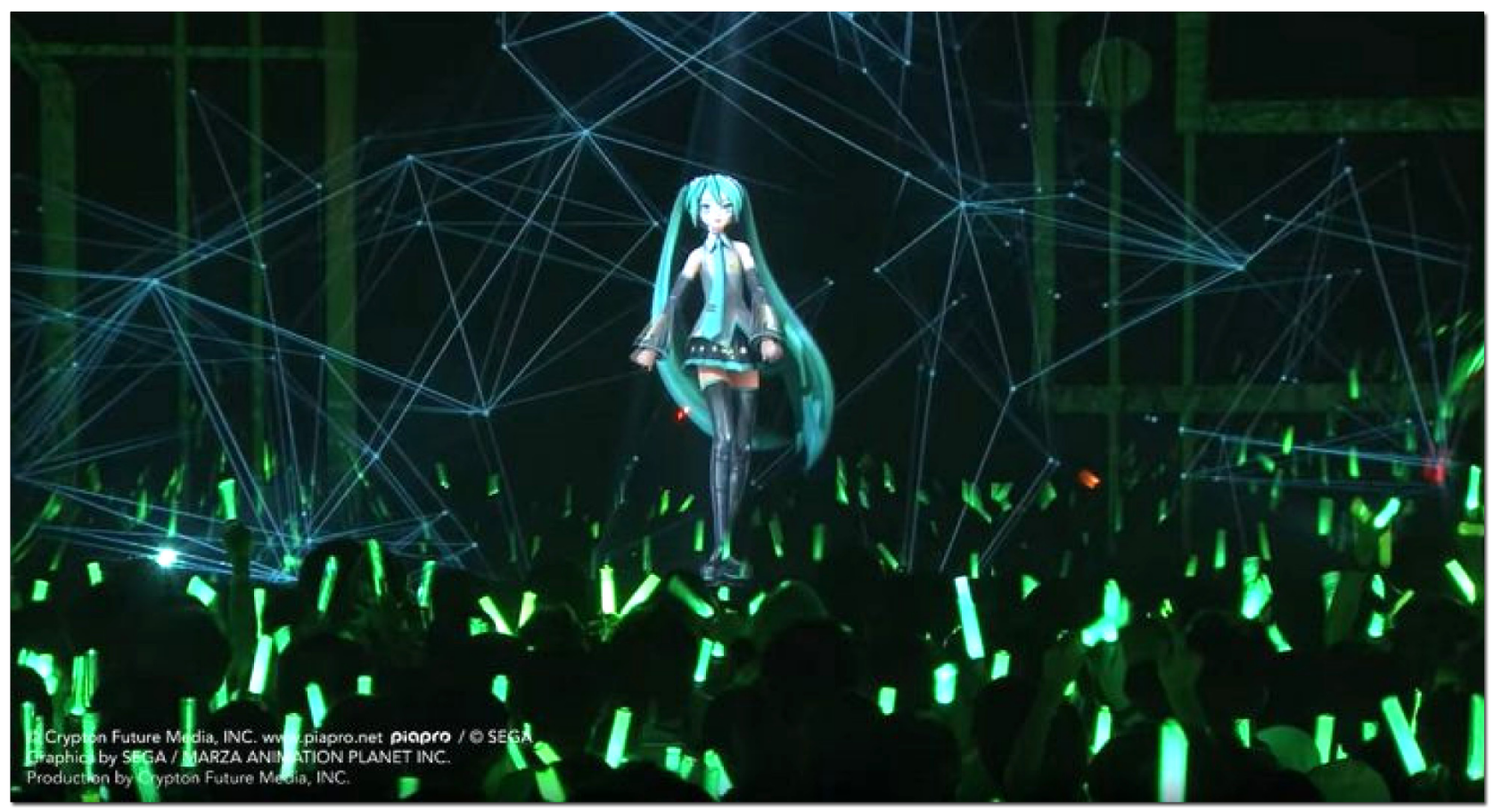

Figure 7. Hatsune Miku's live performance in London 2018 by (C) Crypton Future Media

Source: https://jrocknews.com/2019/03/live-report-hatsune-miku-sold-out-show-in-london.html 
Next to virtual idols, today we talk about holographic three-dimensional telepresence. It is assumed that, just like the internet or virtual reality, 3D holograms will change the way we interact with others. It may be the next disruptor for society and change the way we create and share knowledge (Lee, 2013). In a major advance, Dreshaj (2015) designed 'Holosuite', an end-to-end 3D telepresence software application to favour interactive telepresence. It is a powerful collaborative and interactive tool that offers a big advantage for design teams who can control real-world objects remotely, build artifacts together, and manipulate them infinitely. The interface also allows users to pick up visual cues from the partner's body language (Dreshaj, 2015), thus enhancing the feeling of presence, especially because the 3D images can be seen from all angles. Recent work (Ahmed \& Ahmed, 2021) has shown that holographic technology enhances designers' creativity and innovative skills. As 3D holographic technology continues to advance, we can observe its positive impact on our life and its potential applications in different fields, whether in design (e.g., Ahmed et al., 2021; Dreshaj, 2015), in education (e.g., Lee, 2013; Shuguang \& Lin, 2020), or in the health sector (e.g., Saito et al., 2020).

\section{CONCLUSION}

In this paper, we have reported on major findings concerning the analysis of designers' cognitive processes involved in creativity and we presented some of the difficulties that they encounter during individual and collective design activities. These descriptions were complemented by examples of physical and virtual technology-based tools that can support design process and creative ideas generation. Finally, we evoked perspectives towards the development of innovative new tools that could enhance creative performance in individual and collective situations. Thus, this paper can offer to professionals, and particularly to designers, information elements that can be taken into consideration to decide to use, now or in the future, particular technologies in their practice. Indeed, despite some technological limitations (e.g., Clifton \& Palmisano, 2020), the eventual cost of new hardware and frequent resistance to technological change, we consider that professionals concerned with creativity and innovation should be more aware and informed about such systems, not only because they will become increasingly present in our daily lives but also because they have positive effects on their performance (Thornhill-Miller \& Dupont, 2016).

\section{References}

Abdelhameed, W.A. (2013). Virtual Reality Use in Architectural Design Studios: A case of studying structure and construction. Procedia Computer Science, 25, 220-230. https://doi.org/10.1016/j.procs.2013.11.027

Ahmed, N.H., \& Ahmed, M.S. (2021). The effective use of holographic technology in enhancing the creative thinking of the advertising designer. International Design Journal, 11(2), 247-256. https://doi. org/10.21608/IDJ.2021.152357

Ahn, S.J., Le, A.M.T., \& Bailenson, J. (2013). The effect of embodied experiences on self-other merging, attitude, and helping behavior. Media Psychology, 16(1), 7-38. https://doi.org/10.1080/15213269.2012.75 5877 
Akchelov, E., \& Galanina, E. (2016). Virtual World of Video Games. In $20168^{\text {th }}$ International Conference on Games and Virtual Worlds for Serious Applications (VS-GAMES) (pp. 1-4). IEEE. http://dx.doi.org/10.1109/ VS-GAMES.2016.7590379

Aneja, D., McDuff, D., \& Shah, S. (2019). A high-fidelity open embodied avatar with lip syncing and expression capabilities. In 2019 International Conference on Multimodal Interaction (pp. 69-73). http://dx.doi. org/10.1145/3340555.3353744

Bakr, A.F., El Sayad, Z.T., \& Thomas, S.M.S. (2018). Virtual reality as a tool for children's participation in kindergarten design process. Alexandria Engineering Journal, 57(4), 3851-3861. http://dx.doi.org/10.1016/ j.aej.2018.10.003

Banakou, D., Kishore, S., \& Slater, M. (2018). Virtually being Einstein results in an improvement in cognitive task performance and a decrease in age bias. Frontiers in Psychology, 9, 917. https://doi.org/10.3389/fpsyg.2018.00917

Banerjee, D., \& Rai, M. (2020). Social isolation in Covid-19: The impact of loneliness. https://doi.org/10.1177/002 0764020922269

Barrero, J. M., Bloom, N., \& Davis, S.J. (2021). Why working from home will stick (No. w28731). National Bureau of Economic Research. https://doi.org/10.3386/w28731

Bertrand, P., Guegan, J., Robieux, L., McCall, C.A., \& Zenasni, F. (2018). Learning empathy through virtual reality: multiple strategies for training empathy-related abilities using body ownership illusions in embodied virtual reality. Frontiers in Robotics and Al, 5, 26. https://doi.org/10.3389/frobt.2018.00026

Bhagwatwar, A., Massey, A., \& Dennis, A.R. (2013). Creative Virtual Environments: Effect of Supraliminal Priming on Team Brainstorming. 2013 46th Hawaii International Conference on System Sciences, 215-224. https://doi.org/10.1109/HICSS.2013.152

Bilda, Z., \& Demirkan, H. (2003). An insight on designers' sketching activities in traditional versus digital media. Design studies, 24(1), 27-50. http://dx.doi.org/10.1016/S0142-694X(02)00032-7

Bonnardel, N. (2000). Towards understanding and supporting creativity in design: Analogies in a constrained cognitive environment. Knowledge-Based Systems, 13, 505-513. http://dx.doi.org/10.1016/ S0950-7051(00)00067-8

Bonnardel, N. (2012a). Designing future products: What difficulties do designers encounter and how can their creative process be supported? Work, A Journal of Prevention, Assessment \& Rehabilitation, http:// dx.doi.org/10.3233/WOR-2012-0020-5296

Bonnardel, N. (2012b, reedition). Créativité et Conception: Approches cognitives et ergonomiques [Creativity and Design: Cognitive and Ergonomics Approaches]. De Boeck.

Bonnardel, N., \& Bouchard, C. (2011). Towards supporting creative design: Analysis of the use of the TRENDS system according to designers' expertise. Proceedings of the $8^{\text {th }}$ ACM Conference on Creativity and Cognition - C\&C 2011 (pp. 315-316), Atlanta. New York: ACM Press. https://doi.org/10.1145/2069618.2069674

Bonnardel, N., \& Bouchard, C. (2014). Design, ergonomics and user interfaces: complementary and interdisciplinary studies to enhance creative activities. In Proceedings of the 2014 Ergonomie et Informatique Avancée Conference-Design, Ergonomie et IHM: quelle articulation pour la co-conception de l'interaction (pp. 2-10). https://doi.org/10.1145/2671470.2671471

Bonnardel, N., \& Bouchard, C. (2017). Creativity in design. In J.C. Kaufman, V.P. Glaveanu, \& J. Baer (Eds.), Cambridge Handbook of Creativity Across Different Domains (pp. 403-427). New York: Cambridge University.

Bonnardel, N., Forens, M., \& Lefevre, M. (2016). Enhancing collective creative design: an exploratory study on the influence of static and dynamic personas in a virtual environment. The Design Journal, 19(2), 221-235. http://dx.doi.org/10.1080/14606925.2016.1129145

Bonnardel, N. \& Gero, J. (2021). The possible of design. In V.P. Glăveanu (Ed.), The Palgrave Encyclopedia of the Possible. New York: Palgrave Macmillan.

Bonnardel, N., \& Marmèche, E. (2004). Evocation processes by novice and expert designers: Towards stimulating analogical thinking. Creativity and Innovation Management, 13(3), 176-186. http://dx.doi. org/10.1111/j.0963-1690.2004.00307.x

Bonnardel, N., \& Marmèche, E. (2005). Towards supporting evocation processes in creative design: A cognitive approach. International Journal of Human-Computer Studies, 63(4-5), 422-435. http://dx.doi. org/10.1016/j.ijhcs.2005.04.006 
Bonnardel, N., \& Pichot, N. (2020). Enhancing collaborative creativity with virtual dynamic personas. Applied Ergonomics, 82, 102949. https://doi.org/10.1016/j.apergo.2019.102949

Bonnardel, N., \& Sumner, T. (1996). Supporting evaluation in design. Acta Psychologica, 91(3), 221-244. https://doi.org/10.1016/0001-6918(95)00057-7

Bonnardel, N., Wojtczuk, A., Gilles, P.-Y, \& Mazon, S. (2018). The creative process in design. In T. Lubart (Ed.), The Creative Process: Perspectives from multiple domains (pp. 229-254). New York: Palgrave Macmillan. http://dx.doi.org/10.1057/978-1-137-50563-7_9

Bonnardel, N., \& Zenasni, F. (2010). The impact of technology on creativity in design: An enhancement? Creativity and Innovation Management, 19(2), 180-191. http://dx.doi.org/10.1111/j.1467-8691.2010.00560.x

Bouchard, C., Camous, R., \& Aoussat, A. (2005). Nature and role of intermediate representations (IR) in the design process: Case studies in car design. International Journal of Vehicle Design, 38(1). http://dx.doi. org/10.1504/IJVD.2005.006602

Bouchard, C., \& Omhover, J.F. (2016). Supporting early design through conjoint trends analysis methods and the TRENDS system. In Collaboration in Creative Design (pp. 53-72). Springer, Cham. http://dx.doi. org/10.1007/978-3-319-29155-0_4

Boughzala, I., de Vreede, G.J., \& Limayem, M. (2012). Team collaboration in virtual worlds: Editorial to the special issue. Journal of the Association for Information Systems, 13(10), 6.10.17705/1jais.00313

Bourgeois-Bougrine, S., Richard, P., Burkhardt, J.M., Frantz, B., \& Lubart, T. (2020). The expression of users' creative potential in virtual and real environments: An exploratory study. Creativity Research Journal, 32(1), 55-65. https://doi.org/10.1080/10400419.2020.1712162

Brangier, E., Bornet, C., Bastien, J.M.C., Michel, G., \& Vivian, R. (2011). Mesure de la capacité des personas à générer des idées dans la conception de projets WEB. Le Travail Humain, 75(2), 121-145.

Buisine, S., \& Guegan, J. (2020). Proteus vs. social identity effects on virtual brainstorming. Behaviour \& Information Technology, 39(5), 594-606. https://doi.org/10.1080/0144929X.2019.1605408

Buisine, S., Guegan, J., \& Vernier, F. (2017). Technological innovation in group creativity. In Creativity, Design Thinking and Interdisciplinarity (pp. 185-201). Springer, Singapore. http://dx.doi.org/10.1007/978-98110-7524-7_12

Burkhardt, J.-M., \& Lubart, T. (2010). Creativity in the age of emerging technology. Creativity and Innovation Management, 19, 160-166. https://doi.org/10.1111/j.1467-8691.2010.00559.x

Carillo, K., Cachat-Rosset, G., Marsan, J., Saba, T., \& Klarsfeld, A. (2020). Adjusting to epidemic-induced telework: empirical insights from teleworkers in France. European Journal of Information Systems, http:// dx.doi.org/10.1080/0960085X.2020.1829512

Chinowsky, P.S., \& Rojas, E.M. (2003). Virtual teams: Guide to successful implementation. Journal of Management in Engineering, 19(3), 98-106. http://dx.doi.org/10.1061/(ASCE)0742-597X(2003)19:3(98)

Chrysikou, E.G., \& Weisberg, R.W. (2005). Following the wrong footsteps: Fixation effects of pictorial examples in a design problem-solving task. Journal of Experimental Psychology: Learning, Memory and Cognition, 31, 1134-1148. https://doi.org/10.1037/0278-7393.31.5.1134

Clifton, J., \& Palmisano, S. (2020). Effects of steering locomotion and teleporting on cybersickness and presence in HMD-based virtual reality. Virtual Reality, 24(3), 453-468. http://dx.doi.org/10.1007/s10055-01900407-8

Coburn, J.Q., Freeman, I., \& Salmon, J.L. (2017). A review of the capabilities of current low-cost virtual reality technology and its potential to enhance the design process. Journal of computing and Information Science in Engineering, 17(3), 031013. https://doi.org/10.1115/1.4036921

Dan, A., \& Reiner, M. (2017). EEG-based cognitive load of processing events in 3D virtual worlds is lower than processing events in 2D displays. International Journal of Psychophysiology, 122, 75-84. http://dx.doi. org/10.1016/j.ijpsycho.2016.08.013

Davis, A., Murphy, J.D., Owens, D., Khazanchi, D., \& Zigurs, I. (2009). Avatars, people, and virtual worlds: Foundations for research in metaverses. Journal of the Association for Information Systems, 10(2), 90 117. http://dx.doi.org/10.17705/1jais.00183

Dennis, A.R., Minas, R.K., \& Williams, M.L (2019). Creativity in computer-mediated virtual groups. In P.B. Paulus., \& B.A. Nijstad (Eds.), The Oxford Handbook of Group Creativity and Innovation (pp. 253-269). Oxford: Oxford University Press. https://doi.org/10.1093/oxfordhb/9780190648077.013.15 
Dennis, A.R., \& Wixom, B.H. (2002). Investigating the moderators of the group support systems use with meta-analysis. Journal of Management Information Systems, 18(3), 235-257. https://doi.org/10.1080/074 21222.2002.11045696

Dorst, K., \& Cross, N. (2001). Creativity in the design process: Co-evolution of problem solution. Design Studies, 22, 425-437. http://dx.doi.org/10.1016/S0142-694X(01)00009-6

Dreshaj, E. (2015). Holosuite: an exploration into interactive holographic telepresence (PhD thesis). Boston, MA: Massachusetts Institute of Technology.

Eastman, C.M. (1969). Cognitive processes and ill-defined problems: A case study from design. Proceedings of the 1st International Joint Conference on Artificial Intelligence (pp. 669-690). Washington, DC.

Elmorshidy, A. (2010). Holographic Projection Technology: The World is Changing. ArXiv:1006.0846 [Cs]. http://arxiv.org/abs/1006.0846

Fauville, G., Luo, M., Muller Queiroz, A.C., Bailenson, J.N., \& Hancock, J. (2021). Zoom Exhaustion \& Fatigue Scale. http://dx.doi.org/10.2139/ssrn.3786329

Fischer, G., Giaccardi, E., Eden, H., Sugimoto, M., \& Ye, Y. (2005). Beyond binary choices: Integrating individual and social creativity. International Journal of Human-Computer Studies, 63(4-5), 482-512. http://dx.doi. org/10.1016/j.ijhcs.2005.04.014

Forens, M., Bonnardel, N., \& Barbier, M.L. (2015). How communication modalities can impact group creativity in multi-user virtual environments. In Proceedings of the European Conference on Cognitive Ergonomics 2015 (pp. 1-4). https://doi.org/10.1145/2788412.2788439

Frank, M.G., \& Gilovich, T. (1988). The dark side of self- and social perception: Black uniforms and aggression in professional sports. Journal of Personality and Social Psychology, 54(1), 74-85. https://doi. org/10.1037/0022-3514.54.1.74

Funke, G.J., \& Galster, S.M. (2009). The effects of cognitive processing load and collaboration technology on team performance in a simulated command and control environment. International Journal of Industrial Ergonomics, 39(3), 541-547. https://doi.org/10.1016/j.ergon.2008.10.007

Gero, J.S. (2000). Computational models of innovative and creative design processes. Technological Forecasting and Social Change, 64, 183-196. http://dx.doi.org/10.1016/S0040-1625(99)00105-5

Gero, J.S. \& Bonnardel, N. (Eds.). (2005). Studying Designers. Sydney: University of Sydney.

Gerry, L.J. (2017). Paint with Me: Stimulating Creativity and Empathy While Painting with a Painter in Virtual Reality. IEEE Transactions on Visualization and Computer Graphics, 23(4), 1418-1426. https://doi. org/10.1109/TVCG.2017.2657239

Girvan, C. (2018). What is a virtual world? Definition and classification. Educational Technology Research and Development, 66(5), 1087-1100. http://dx.doi.org/10.1007/s11423-018-9577-y

Goh, C.H., Kulathuramaiyer, N., \& Zaman, T. (2017). Riding waves of change: a review of personas research landscape based on the three waves of $\mathrm{HCl}$. In International Conference on Social Implications of Computers in Developing Countries (pp. 605-616). Springer, Cham. https://doi.org/10.1007/978-3-319-591117_49

Goldschmidt, G. (1991). The dialectics of sketching. Creativity Research Journal, 4, 123-143. http://dx.doi.org/ $10.1080 / 10400419109534381$

Guan, J.-Q., Wang, L.-H., Chen, Q., Jin, K., \& Hwang, G.-J. (2021). Effects of a virtual reality-based pottery making approach on junior high school students' creativity and learning engagement. Interactive Learning Environments, O(0), 1-17. https://doi.org/10.1080/10494820.2021.1871631

Guegan, J., Buisine, S., Mantelet, F., Maranzana, N., \& Segonds, F. (2016). Avatar-mediated creativity: When embodying inventors makes engineers more creative. Computers in Human Behavior, 61. http://dx.doi. org/10.1016/j.chb.2016.03.024

Guegan, J., Segonds, F., Barré, J., Maranzana, N., Mantelet, F., \& Buisine, S. (2017). Social identity cues to improve creativity and identification in face-to-face and virtual groups. Computers in Human Behavior, 77, 140-147. https://doi.org/10.1016/j.chb.2017.08.043

Gül, L.F., \& Maher, M.L. (2009). Co-creating external design representations: Comparing face-to-face sketching to designing in virtual environments. CoDesign, 5(2), 117-138. http://dx.doi.org/10.1080/15710880 902921422

Halo, L., \& Matsutoya, M. (2019). Still be here. The Multiplicity of Hatsune Miku. Interface Critique, 2, 143-149. https://doi.org/10.11588/ic.2019.2.66988 
Hayashi, K. (2021). Holograms and Idols: The Image of God and Artificial Transcendence in the Cultural Phenomenon of the Japanese Vocaloid Hatsune Miku. Technology and Theology, 263.

Jansson, D.G., \& Smith, S.M. (1991). Design fixation. Design Studies, 12, 3-11. https://doi.org/10.1016/0142694X(91)90003-F

Jensen, M.M., Thiel, S.K., Hoggan, E., \& Bødker, S. (2018). Physical versus digital sticky notes in collaborative ideation. Computer Supported Cooperative Work (CSCW), 27(3), 609-645. http://dx.doi.org/10.1007/ s10606-018-9325-1

Johnson, R.D., \& Downing, L.L. (1979). Deindividuation and valence of cues: effects on prosocial and antisocial behavior. Journal of Personality and Social Psychology, 37(9), 1532-1538. https://doi.org/10.1037/00223514.37.9.1532

Karau, S.J., \& Hart, J.W. (1998). Group cohesiveness and social loafing: Effects of a social interaction manipulation on individual motivation within groups. Group Dynamics: Theory, Research, and Practice, 2(3), 185. https://doi.org/10.1037/1089-2699.2.3.185

Karau, S.J., \& Williams, K.D. (1997). The effects of group cohesiveness on social loafing and social compensation. Group Dynamics: Theory, Research, and Practice, 1(2), 156. https://doi.org/10.1037/10892699.1.2.156

Khosravi, P., Rezvani, A., \& Wiewiora, A. (2016). The impact of technology on older adults' social isolation. Computers in Human Behavior, 63, 594-603. https://doi.org/10.1016/j.chb.2016.05.092

Kirkman, B.L., \& Mathieu, J.E. (2005). The dimensions and antecedents of team virtuality. Journal of Management, 31(5), 700-718. http://dx.doi.org/10.1177/0149206305279113

Kohler, T., Matzler, K., \& Füller, J. (2009). Avatar-based innovation: Using virtual worlds for real-world innovation. Technovation, 29(6-7), 395-407. http://dx.doi.org/10.1016/j.technovation.2008.11.004

Koutsabasis, P., Vosinakis, S., Malisova, K., \& Paparounas, N. (2012). On the value of virtual worlds for collaborative design. Design Studies, 33(4), 357-390. http://dx.doi.org/10.1016/j.destud.2011.11.004

Lee, H. (2013). 3D holographic technology and its educational potential. TechTrends, 57(4), 34-39. https://doi. org/10.1007/s11528-013-0675-8

Liu, Y., Lather, J., \& Messner, J. (2014). Virtual reality to support the integrated design process: A retrofit case study. In Computing in Civil and Building Engineering (2014) (pp. 801-808). http://dx.doi.org/10.1061/97 80784413616.100

Maaravi, Y., Heller, B., Shoham, Y., Mohar, S., \& Deutsch, B. (2020). Ideation in the digital age: literature review and integrative model for electronic brainstorming. Review of Managerial Science. http://dx.doi. org/10.1007/s11846-020-00400-5

Maciver, F., \& Malins, J. (2016). Two Heads Are Better Than One: Principles for Collaborative Design Practice. In P. Markopoulos, J.-B. Martens, J. Malins, K. Coninx, \& A. Liapis (Eds.), Collaboration in Creative Design: Methods and Tools (1 ed., Vol. 1, pp. 13-31). Springer. https://doi.org/10.1007/978-3-319-29155-0_2

Marinussen, M., \& de Rooij, A. (2019). Being yourself to be creative: How using self-similar avatars can support the generation of original ideas in virtual environments. 285-293. Paper presented at ACM Creativity and Cognition 2019, San Diego, United States. https://doi.org/10.1145/3325480.3325482

McKinlay, A., Procter, R., \& Dunnett, A. (1999). An investigation of social loafing and social compensation in computer-supported cooperative work. In Proceedings of the international ACM SIGGROUP conference on Supporting group work (pp. 249-257). https://doi.org/10.1145/320297.320327

Merrick, K. E., \& Gu, N. (2011). Case studies using multiuser virtual worlds as an innovative platform for collaborative design. Journal of Information Technology in Construction (ITcon), 16(12), 165-188.

Miaskiewicz, T., \& Kozar, K.A. (2011). Personas and user-centered design: How can personas benefit product design processes? Design studies, 32(5), 417-430. http://dx.doi.org/10.1016/j.destud.2011.03.003

Michinov, N. (2012). Is electronic brainstorming or brainwriting the best way to improve creative performance in groups? An overlooked comparison of two idea-generation techniques. Journal of Applied Social Psychology, 42, E222-E243. https://doi.org/10.1111/j.1559-1816.2012.01024.x

Michinov, N., \& Primois, C. (2005). Improving productivity and creativity in online groups through social comparison process: New evidence for asynchronous electronic brainstorming. Computers in Human Behavior, 21(1), 11-28. https://doi.org/10.1016/j.chb.2004.02.004 
Moreno, D.P., Yang, M.C., Hernández, A.A., Linsey, J.S., \& Wood, K.L. (2015). A step beyond to overcome design fixation: a design-by-analogy approach. In Design Computing and Cognition'14 (pp. 607-624). Springer, Cham. http://dx.doi.org/10.1007/978-3-319-14956-1_34

Müller, F. A., \& Wulf, T. (2021). Differences in Learning Effectiveness across Learning Environments: A Cognitive Load Perspective. In Academy of Management Proceedings (Vol. 2021, No. 1, p. 11426). Briarcliff Manor, NY 10510: Academy of Management.

Nemeth, C.J., \& Nemeth-Brown, B. (2003). Better than individuals? The potential benefits of dissent and diversity for group creativity. In P.B. Paulus \& B.A. Nijstad (Eds.), Group creativity: Innovation through collaboration (pp. 63-84). Oxford University Press. https://doi.org/10.1093/acprof:oso/9780195147308 .003 .0004

Nijstad, B.A., Stroebe, W., \& Lodewijkx, H.F. (2003). Production blocking and idea generation: Does blocking interfere with cognitive processes? Journal of Experimental Social Psychology, 39(6), 531-548. https:// doi.org/10.1016/S0022-1031(03)00040-4

Nunamaker, J.F., Dennis, A.R., Valacich, J.S., Vogel, D., \& George, J.F. (1991). Electronic meeting systems. Communications of the ACM, 34(7), 40-61. https://doi.org/10.1145/105783.105793

O'Connor, M.F., Arizmendi, B.J., \& Kaszniak, A.W. (2014). Virtually supportive: a feasibility pilot study of an online support group for dementia caregivers in a 3D virtual environment. Journal of Aging Studies, 30, 87-93. http://dx.doi.org/10.1016/j.jaging.2014.03.001

Osborn, A.F., (1963). (2nd). Applied Imagination. New York, Scribner.

Paulus, P.B., \& Brown, V.R. (2007). Toward a more creative and innovative group idea generation: a cognitive-social-motivational perspective of brainstorming. Social Personality and Psychology Compass, 1, 248-165. http://dx.doi.org/10.1111/j.1751-9004.2007.00006.x

Paulus, P.B., \& Kenworthy, J.B. (2019). Effective brainstorming. In P.B. Paulus., \& B.A. Nijstad (Eds.), The Oxford Handbook of Group Creativity and Innovation (pp. 287-306). Oxford: Oxford University Press. http:// dx.doi.org/10.1093/oxfordhb/9780190648077.013.17

Paulus, P.B., Kohn, N.W., Arditti, L.E., \& Korde, R.M. (2013). Understanding the group size effect in electronic brainstorming. Small Group Research, 44(3), 332-352. https://doi.org/10.1177/1046496413479674

Paulus, P.B., Larey, T.S., \& Ortega, A.H. (1995). Performance and perceptions of brainstormers in an organizational setting. Basic and Applied Social Psychology, 17(1-2), 249-265. https://doi.org/10.1080/01973533. 1995.9646143

Paulus, P.B., \& Nijstad, B.A. (Eds.). (2003). Group creativity: Innovation through collaboration. Oxford: Oxford University Press. https://doi.org/10.1093/acprof:oso/9780195147308.001.0001

Pissini, J. (2020). Embodied by Design: The Presence of Creativity, Art-making, and Self in Virtual Reality. (Electronic Thesis or Dissertation). Retrieved from https://etd.ohiolink.edu/

Pruitt, J., \& Grudin, J., (2003). Personas: practice and theory. In: Proceedings of the Conference on Designing for User Experiences. ACM, New York, pp. 1-15. https://doi.org/10.1145/997078.997089

Ratan, R., Beyea, D., Li, B. J., \& Graciano, L. (2020). Avatar characteristics induce users' behavioral conformity with small-to-medium effect sizes: A meta-analysis of the proteus effect. Media Psychology, 23(5), 651-675. https://doi.org/10.1080/15213269.2019.1623698

Raveendhran, R., Fast, N.J., \& Carnevale, P.J. (2020). Virtual (freedom from) reality: Evaluation apprehension and leaders' preference for communicating through avatars. Computers in Human Behavior, 111, 106415. http://dx.doi.org/10.1016/j.chb.2020.106415

Reiter-Palmon, R., Kramer, W., Allen, J.A., Murugavel, V.R., \& Leone, S.A. (2021). Team creativity during virtual meetings. Creativity. Theories - Research - Applications, 8(1), 165-188.

Reitman, W.R. (1964). Heuristic decision procedures, open constraints, and the structure of ill-defined problems. Human Judgments and Optimality, 282-315.

Saito, Y., Sugimoto, M., Imura, S., Morine, Y., Ikemoto, T., Iwahashi, S., ... \& Shimada, M. (2020). Intraoperative 3D hologram support with mixed reality techniques in liver surgery. Annals Of Surgery, 271(1), e4-e7. http://dx.doi.org/10.1097/SLA.0000000000003552

Schön, D.A. (1983). The reflective practitioner: How professionals think in action. New York: Basic Books. (Reprinted in 1995).

Schroeder, R. (2008). Defining virtual worlds and virtual environments. Journal For Virtual Worlds Research, 1(1). https://doi.org/10.4101/jvwr.v1i1.294 
Shuguang, L.I.U., \& Lin, B.A. (2020). Holographic Classroom Based on Digital Twin and Its Application Prospect. In 2020 IEEE 3rd International Conference on Electronics and Communication Engineering (ICECE) (pp. 122-126). IEEE.

Sosik, J.J., Kahai, S.S., \& Avolio, B.J. (1998). Transformational leadership and dimensions of creativity: Motivating idea generation in computer-mediated groups. Creativity Research Journal, 11(2), 111-121. https:// doi.org/10.1207/s15326934crj1102_3

Suler, J. (2004). The online disinhibition effect. Cyberpsychology \& behavior, 7(3), 321-326. https://doi.org/10. $1089 / 1094931041291295$

Sung, R.C., Ritchie, J.M., Robinson, G., Day, P.N., Corney, J.R., \& Lim, T. (2009). Automated design process modelling and analysis using immersive virtual reality. Computer-Aided Design, 41(12), 1082-1094. https://doi.org/10.1016/j.cad.2009.09.006

Suwa, M., Gero, J., \& Purcell, T. (1998). Analysis of cognitive processes of a designer as the foundation for support tools. in J.S. Gero \& F. Sudweeks (Eds), Proc. of Artificial Intelligence in Design, 98, (pp. 229-247). Kluwer, Dordrecht, The Netherlands. http://dx.doi.org/10.1007/978-94-011-5121-4_12

Suwa, M., Gero, J.S., \& Purcell, T. (2000). Unexpected discoveries and s-inventions of design requirements: Important vehicles for a design process. Design Studies, 21(6), 539-567. http://dx.doi.org/10.1016/S0142694X(99)00034-4

Takahashi, D. (2015). Second Life pioneer Philip Rosedale shows off virtual toy room in High Fidelity. Venture Beat. Retrieved from https://venturebeat.com/2015/10/28/virtual-world-pioneer-philip-rosedaleshows-off-virtual-toy-room-in-high-fidelity/

Tao, X., Chen, X., Zeng, X., \& Koehl, L. (2018). A customized garment collaborative design process by using virtual reality and sensory evaluation on garment fit. Computers \& Industrial Engineering, 115, 683-695. http://dx.doi.org/10.1016/j.cie.2017.10.023

Thornhill-Miller, B., \& Dupont, J.M. (2016). Virtual reality and the enhancement of creativity and innovation: Under recognized potential among converging technologies? Journal of Cognitive Education and Psychology, 15(1), 102-121. http://dx.doi.org/10.1891/1945-8959.15.1.102

Toney, S., Light, J., \& Urbaczewski, A. (2021). Fighting Zoom fatigue: Keeping the zoombies at bay. Communications of the Association for Information Systems, 48(1), 10. https://doi.org/10.17705/1CAIS.04806

Visser, W. (1994). Organisation of design activities: Opportunistic, with hierarchical episodes. Interacting with Computers, 6, 235-238. https://doi.org/10.1016/0953-5438(94)90014-0

Wiederhold, B.K. (2013). Avatars: changing behavior for better or for worse? CyberPsychology, Behavior, \& Social Networking, 16, 319-320. http://dx.doi.org/10.1089/cyber.2013.1517

Yee, N., \& Bailenson, J. (2007). The Proteus effect: The effect of transformed self-representation on behavior. Human Communication Research, 33(3), 271-290. http://dx.doi.org/10.1111/j.1468-2958.2007.00299.x

Ziegler, R., Diehl, M., \& Zijlstra, G. (2000). Idea production in nominal and virtual groups: Does computermediated communication improve group brainstorming?. Group Processes \& Intergroup Relations, 3(2), 141-158. https://doi.org/10.1177/1368430200032003

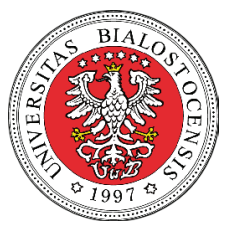

(c) Copyright by Faculty of Education, University of Bialystok,

20 Swierkowa St., 15-328 Bialystok, Poland

tel. +48857457283

e-mail: creativity@uwb.edu.pl

http://www.creativity.uwb.edu.pl 